\title{
The Role of SLC22A4 Gene Polymorphisms in the Response to Salbutamol in Asthmatic Patients
}

\author{
${ }^{1}$ Alshymaa A. Ahmed, ${ }^{2}$ Nora M. Said, ${ }^{3}$ Alia A. El Shahaway and ${ }^{4}$ Nagwan A. Ismail \\ ${ }^{1}$ Department of Clinical Pathology, Faculty of Medicine, \\ Zagazig University, Zagazig City, Al Sharqia Governorate Egypt \\ ${ }^{2}$ Department of Clinical Pathology, Faculty of Medicine, Zagazig University, \\ Zagazig City, Al Sharqia Governorate, Egypt \\ ${ }^{3}$ Department of Medical Microbiology \& Immunology, Faculty of Medicine, \\ Zagazig University, Zagazig City, Al Sharqia Governorate, Egypt \\ ${ }^{4}$ Chest Department, Faculty of Medicine, \\ Zagazig University, Zagazig City, Al Sharqia Governorate, Egypt.
}

Article history

Received: 12-04-2019

Revised: 16-05-2019

Accepted: 29-06-2019

Corresponding Author:

Alshymaa A. Ahmed

Department of Clinical

Pathology, Faculty of

Medicine, Zagazig University,

Zagazig City, Al Sharqia

Governorate Egypt

E-mail: alshymaa2110@gmail.com

\begin{abstract}
Response to Bronchodilators is influenced by many factors including genetics. To evaluate the influence of SLC22A4 gene polymorphisms (rs3792876 and rs2073838) on the response to inhaled salbutamol in asthmatic patients, bronchodilator response was assessed in 180 bronchial asthma patients via measuring changes of the Forced Expiratory Volume in one second (FEV1) after the administration of inhaled salbutamol and genotyping for rs3792876 and rs2073838 was carried out using real-time polymerase chain reaction. Frequencies of genotypes were compared in between responders and non-responders. The frequency of rs2073838 genotypes showed no significant differences. On the other hand, the recessive genotype of rs3792876 occurred more frequently among the non-responding patients $\mathrm{P}=0.01,95 \%$ confidence interval (1.2-9.5). The homozygous form of rs3792876 can influence the absorption of inhaled bronchodilator (Salbutamol), although, replication studies on this point are recommended.
\end{abstract}

Keywords: Bronchial Asthma, OCTN1, SLC22A4, Bronchodilator Response, Salbutamol

\section{Introduction}

Bronchial asthma is one of the most prevalent chronic respiratory disorders affecting around 358 million people worldwide (Soriano et al., 2017). Despite the growing understanding of its pathogenesis and the advances of the management guidelines, inadequate control of asthma still presents a serious problem (Pauwels, 1996), as patients with inadequately controlled asthma often have limited therapeutic options and remain at high risk of serious morbidity and mortality (Chung et al., 1996). The aim of asthma pharmacogenetics is to reduce the asthma burden via utilizing genetic information to personalize asthma pharmacotherapy. Novel gene variants have been identified to influence the response to commonly used asthma drugs. Studies to identify novel polymorphisms that associate with response to asthma drugs are still required (Lima et al., 2009).

The milestone drug in relieving asthma symptoms are the inhaled bronchodilators including the adrenergic $\beta_{2}$ receptor agonists and the anticholinergic drugs. Many factors underlying the large standard deviation of Bronchodilator Response (BDR), these factors include personal, environmental as well as inherited genetic factors (Tarnoki et al., 2015). Effective and rapid absorption of inhaled bronchodilators across the airway epithelium is a prerequisite to reach their targets in the smooth muscle layer. The majority of the currently used bronchodilators are cationic in the physiologic $\mathrm{pH}$, they cannot diffuse freely through the airway epithelial cell membrane lipid bilayer and so, transporters are required to facilitate the transmission of these organic cations through the cell membrane barriers (Horvath et al., 2006).

A number of polyspecific transporters that facilitate the passage of drugs through the membrane barriers have been identified. These include the Solute Carrier (SLC) transporter family (Horvath et al., 2006). Solute Carrier (SLC) is a superfamily of transporters including over 300 members divided into 52 families. Solute carriers mediate the influx of a diverse range of compounds including both endobiotic and exogenous chemicals 
(Zhou and You, 2007; Koepsell and Endou, 2003). Two main subfamilies of human SLC transporters have been identified, Organic Cation Transporters (OCT, encoded by SLC22A1 - 22A5 genes) and organic anion transporters (OAT, encoded by SLC22A6- 22A11 genes) (Okuda et al., 1996; Kekuda et al., 1998; Gründemann et al., 1997).

Organic Cation Transporters include electrogenic transporters (i.e., OCT1/SLC22A1, OCT2/SLC22A2 and OCT3/SLC22A3) and electroneutral PH dependent transporters named (OCTN1/SLC22A4 and OCTN2/SLC22A5) (Ayrton and Morgan, 2008). Organic cation transporters share a common topological structure that contains twelve transmembrane domains, an intracellular $\mathrm{N}$ - and C-terminus with a large extracellular loop between the first and second transmembrane domains (Koepsell and Endou, 2004).

The Organic Cation Transporter (OCTN1) is expressed in different tissues like kidney, muscles and bone marrow cells (Tamai et al., 1997). Initially, it was known as a carnitine transporter, but recently, Lergothioneine "the xenobiotic amino acid" is considered to be its main physiological substrate (Grundemann et al., 2005). It can transport zwitterions, as well as several organic cationic drugs at both directions (Tamai et al., 1997). Sakamoto et al. (2013) found that OCTN1 was highly expressed in the lung (Sakamoto et al., 2013).

The SLC22A4 gene encodes for the OCTN1 and is located on chromosome $5 q 31$. This chromosome region contains multiple genes involved in immune response (Santiago et al., 2006). SLC22A4 gene polymorphisms have been implicated to be associated with increased incidences of autoimmune and inflammatory disorders such as; rheumatoid arthritis, type 1 diabetes mellitus, inflammatory bowel diseases and bronchial asthma (Santiago et al., 2006; Tokuhiro et al., 2003; Peltekova et al., 2004; Li et al., 2012). In addition; Single Nucleotide Polymorphisms (SNPs) of SLC22A4 have received a great attention in clinical fields as they can modulate the transporter gene expression and functions, causing individual variations in response to drugs (Nakahara et al., 2008; Hou et al., 2015), such as the association of rs460089 and rs1050152 with Imatinib therapy outcome in chronic myeloid leukemia patients (Jaruskova et al., 2017; Angelini et al., 2013).

Intron 1 point mutation $\mathrm{rs} 3792876 \mathrm{~T} / \mathrm{C}(\mathrm{slc} 2 \mathrm{~F} 2)$ in SLC22A4 gene affects binding of runt-related transcription factor (RUNX1), regulating the transcription of SLC22A4 (Hou et al., 2015). The recessive genotype of slc2F2 showed a positive association with autoimmune diseases including Rheumatoid arthritis, autoimmune thyroiditis and Crohn's disease (Hou et al., 2015; Jaruskova et al., 2017; Angelini et al., 2013; De Ridder et al., 2007). Another polymorphism; rs2073838 A/G (slc2F1) is on intron 2 of SLC22A4 gene (Barton et al., 2005), which also showed a positive association with Rheumatoid arthritis (Hou et al., 2015).

\section{Research Hypothesis}

Based on the molecular function and the frequent associations of these SNPs with autoimmune diseases we hypothesized that rs3792876 and rs2073838 can affect the absorption of inhaled bronchodilators such as the shortacting $\beta_{2}$ Adrenergic receptors agonist (Salbutamol) leading to an impaired response to these drugs.

\section{Objectives of this Work}

To evaluate the influence of SLC22A4 gene polymorphisms on the response to inhaled bronchodilators as the main asthma reliever.

\section{The Aim of this Work}

This may participate in improving asthma therapy outcome in non-responding patients due to genetic causes by rapid shifting to other lines of drugs that relieve asthma symptoms and to encourage the invention of structurally different inhaled bronchodilators.

\section{Methods}

This cross-sectional study was conducted at Clinical Pathology and Chest Departments, Faculty of Medicine, Zagazig University Hospitals in Zagazig city, Al Sharqia Governorate, Egypt, from July 2017 to September 2018. Eligible patients for inclusion were constitutive patients, from both genders, at any age above 7 years old "to be able to participate in pulmonary function tests" and from the same Egyptian ethnicity. Patients were diagnosed to have mild to moderate persistent bronchial asthma and admitted to the chest clinic for follow up and reevaluation. The initial diagnosis of patients was confirmed by revising the medical history of patients including clinical manifestations, examination findings, X-ray films if present and spirometry results including Forced Vital Capacity (FVC), Forced Expiratory Volume in one second (FEV1) and FEV1/FVC ratio. For the diagnosis of asthma and assessing asthma severity; the GINA 2016 criteria was used (http://ginasthma.org/wp-content/uploads/2016/04/GINA2016-main-report_tracked.pdf. Skin prick test was performed at Allergy and Immunology Unit, Zagazig University, under the supervision of the third author. Positive and negative controls were included to validate the prick test.

Patients not on regular treatment, having other complications like bronchiectasis or chest infections and patients who refused or unable to give informed written consent for participation were excluded from the study. Patients with intermittent and severe asthma were excluded as the formers usually seek medical advice at the primary care units during attacks and are lost from follow up for several months (Shahidi and Fitzgerald, 
2010), also, it is difficult to assess BDR in stable asthmatic patients whom there is no resting bronchoconstriction (Koskela et al., 2006), the later were excluded as they are usually resistant to inhaled bronchodilators and already require high doses of inhaled and systemic corticosteroids (Poon et al., 2012).

\section{Data Collection}

Personal, family, past, medical histories and history of atopy were taken from each patient after giving written informed consent. In addition, data from patients' records were collected.

\section{Bronchodilator Reversibility Testing}

Each patient was assessed by measuring the changes of FEV1 in response to inhaled Salbutamol, patients were asked to stop long and short acting $\beta 2$ agonists 12 and 6 hours, respectively and to stop smoking at least one hour, before the assessment. A nose clip was used and the spirometric maneuvers were performed in the standing position. A minimum of 3 maneuvers was done, with a minimum exhalation time of 6 seconds per maneuver, unless there was an obvious plateau (i.e., no volume change) for at least 1 second, or the subject could not exhale further. The paper printout of the volumetime and flow-volume displays were subjected to the acceptability criteria of the American Thoracic Society (ATS); FEV1, FEV1/FVC ratio, post-bronchodilator FEV1were recorded for each patient. A response was considered positive when a change in FEV $1 \geq 12 \%$ and $200 \mathrm{~mL}$ after administration of one to two buffs (200$400 \mu \mathrm{g}$ ) of salbutamol (Larocca et al., 2013). The test was performed by qualified staff members in the chest clinic under the supervision of the fourth author. Patients were classified as Responders (positive BDR) and Non-responders (negative BDR).

\section{Genotyping}

SLC22A4 gene polymorphisms were carried out as follows; Two milliliters of whole blood was withdrawn on EDTA containing BD Vacutainer tubes. DNA extraction using (Thermo Fisher Scientific, USA) kit "according to the manufacturer's guidelines" was carried out by author 1 and 3 in Zagazig University Hospital research lab. The real-time PCR for the studied SNPs was performed in the Central Research Lab of the hospital by a qualified staff member and a well-trained technician under the supervision of the first three authors, on (StepOnePlus ${ }^{\mathrm{TM}}$ Real-Time PCR, Thermo Fisher Scientific, USA). The reaction mixture included; $10 \mathrm{uL}$ from the $\operatorname{TaqMan}^{\mathrm{R}}$ Universal PCR Master Mix (Thermo Fisher Scientific, USA), $0.5 \mathrm{uL}$ from the readymade primer-probe mixture of one SNP (Custom TaqMan ${ }^{\mathrm{R}}$ SNP Genotyping Assays, Thermo Fisher Scientific, USA), $3 \mathrm{uL}$ from the extracted DNA and $6.5 \mathrm{uL}$ nuclease-free water, annealing temperature was set at $60^{\circ} \mathrm{C}$.

\section{Confirmation by DNA Sequencing}

Genotyping of ambiguous samples and confirmation of $10 \%$ of samples was carried in Zagazig University Hospital lab using direct Sanger sequencing: - (1) PCR amplification using the following primers; for rs 2073838 (forward $5 '-$ ACGTTGGATGGAAAAAAGTCTGCCAGAGCC-3', reverse $5^{\prime-}$ ACGTTGGATGTTGCCAAGGTGTGTTGCAAG-3') and for rs3792876 (forward 5'ACGTTGGATGACTGATTCCCACCCA-3' , reverse 5'-ACGTTGGATGCAGAAGTTCCCCGTTA-3')

(Newman et al., 2005). PCR amplification reaction mixture contains, $12.5 \mu \mathrm{L}$ of the ready master mix (Top Taq Master Mix Kit Qiagen, Germany), $1 \mu \mathrm{L}$ of $10 \mathrm{pmol}$ from each primer, $6 \mathrm{ul}$ of genomic DNA, $4.5 \mu \mathrm{L}$ nuclease free water, using thermal cycler (Biometra TProfessional PCR, Germany) with cycling condition of initial denaturation at $95^{\circ} \mathrm{C}$ for $5 \mathrm{~min}, 35$ cycles of (denaturation at $95^{\circ} \mathrm{C}$ for $1 \mathrm{~min}$, annealing at $61^{\circ} \mathrm{C}$ for rs2073838 and $54^{\circ} \mathrm{C}$ for rs3792876 for $40 \mathrm{sec}$ and extension at $72^{\circ} \mathrm{C}$ for $1 \mathrm{~min}$, followed by a final extension at $72^{\circ} \mathrm{C}$ for $10 \mathrm{~min}$ (2) first purification of amplified PCR products with QIAquik PCR Purification Kit (50) (Qiagen GmbH, Hilden, Germany). (3) Cycle sequencing using Bigdye Terminator V3.1cycle sequencing kit (Thermo Fisher Scientific Inc., Ontario, Canada), (4) the second purification of the products using BigDye X Terminator Purification Kit (Thermo Fisher Scientific Inc., Ontario, Canada). (5) Sequencing using the Applied Biosystems 3500 Genetic Analyzer (Thermo Fisher Scientific Inc., Ontario, Canada). All were performed according to manufacturer's guidelines by two qualified staff members under the supervision of the first two authors (6) Nucleotide Blast online program (https://blast.ncbi.nlm.nih.gov) was used for results interpretation.

\section{Statistical Analysis}

SPSS program version 21 (IBM Corp., Chicago, IL, USA) statistical software was used for data analysis. Shapiro-Wilk test was used to test the normality of quantitative results. Ages, BMI and duration of disease are expressed as mean and standard deviation. FEV1, FEV1/FVC and changes in FEV1are expressed as median and range. T-test and Mann Whitney test were used to compare means and medians among the studied groups respectively. Genotypes, haplotype and allele frequencies were expressed as numbers and percentages. The differences in SLC22A4 genotypes as well as haplotypes frequencies among the investigated groups were analyzed using the Chi-square test and the Fisher's exact test for results $\leq 5$. Odds Ratios (ORs) and $95 \%$ confidence intervals were calculated. $\mathrm{P} \leq 0.05$ was considered to indicate statistically significant differences. 


\section{Ethical Approvals}

The Institutional Review Board (IRB) and the ethical committee of Zagazig University Hospitals approved this study. All subjects gave written informed consent before enrollment in this work. Approval number (IRB\#4725/26-6-2017).

\section{Sample Size Calculation}

The sample size of this study was calculated using this formula (Charan and Biswas, 2013):

$$
n=Z_{1-\alpha / 2}^{2} \times p(1-p) / d^{2}
$$

As $\mathrm{Z}_{1-\alpha / 2}$ is the standard normal variate at $1 \%$ type one error $=2.58, p$ is the prevalence of these mutations in normal population $=0.07$ (Newman et al., 2005) and $\mathrm{d}$ is the absolute error or precision $=0.05$. Ten percent of the calculated sample size was added to the final sample size to compensate for lost samples or data.

\section{Results}

A total of 190 patients were eligible for inclusion in this study, four patients with failed spirometry testing and six with failed genotyping were excluded from analysis. The remaining 180 patients included 97(53.9\%) males and $83(46.1 \%)$ females, with mean age \pm SD (29.9 \pm 13.3$)$; range (8-51) years and mean body mass index $\pm \mathrm{SD}$ (27.5 \pm 4.6$)$; range (18.1-37.3) $\mathrm{Kg} / \mathrm{m}^{2}$. Duration since the first diagnosis in these patients ranged from 1 to 36 years with mean \pm SD $15.3 \pm 8.5$. Fourtyeight patients $(26.7 \%)$ were current smokers. Eightythree $(46.1 \%)$ of the included patients had a positive family history of bronchial asthma. 55(33.5\%) patients had associated allergic rhinitis, 20(11.1\%) had allergic rhinitis with conjunctivitis, $8(4.4 \%)$ had allergic rhinitis with dermatitis and one patient $(0.5 \%)$ had allergic rhinitis with conjunctivitis and dermatitis. $89(49.4 \%)$ of patients had positive skin tests for respiratory allergens like pollen, house dust, molds, animal fur and dust mites.

Based on the bronchodilator reversibility test; $105(58.3 \%)$ patients were responders and $75(41.7 \%)$ were not, with median FEV1 absolute and percent changes $(0.30 \mathrm{~L}$ and $15 \%)$ in responders versus $(0.13$ $\mathrm{L}$ and $8 \%$ ) in non-responders $\mathrm{P}<0.01$ as shown in Table 1. The severity of disease, baseline pulmonary function tests and medication history of patients in the two groups were also illustrated in Table 1. There were no significant differences regarding the severity of the disease and baseline pulmonary functions. By taking the history of medications in the past few months, patients with poor response to inhaled bronchodilators required the administration of oral steroids to relieve asthma symptoms during the past 12 months and needed to take maintenance medications and increased rescue medications in the past four months more frequently $\mathrm{P}<0.01$.

A comparison was made between responders and non-responders regarding age, gender, BMI, duration of the diseases, family history, associated allergic diseases and results of skin test, to exclude the possible effect of these factors on the responsiveness to inhaled bronchodilators. Results are summarized in Table 2. No significant differences between the two groups were detected regarding these features.

Table 1: Pulmonary function tests and medical history of patients

\begin{tabular}{|c|c|c|c|c|}
\hline & & $\begin{array}{l}\text { Responders } \\
\mathrm{n}=105\end{array}$ & $\begin{array}{l}\text { Non responders } \\
\mathrm{n}=75\end{array}$ & $\mathrm{P}$ value \\
\hline \multirow[t]{2}{*}{ Asthma severity n(\%) } & Mild & $64(60.9)$ & $36(48.0)$ & 0.08 \\
\hline & Mod & $41(39.1)$ & $39(52.0)$ & \\
\hline \multirow[t]{2}{*}{ Baseline FEV1/FVC\% } & Median & 64 & 62 & 0.06 \\
\hline & Range & $40-75$ & $36-75$ & \\
\hline \multirow[t]{2}{*}{ Baseline FEV1 (litre) } & Median & 2 & 1.85 & 0.06 \\
\hline & Range & $1.5-2.5$ & $1.2-2.4$ & \\
\hline \multirow[t]{2}{*}{ Post BD FEV1 (litre) } & Median & 2.24 & 1.99 & $<0.01$ \\
\hline & Range & $1.69-2.95$ & $1.87-2.54$ & \\
\hline \multirow[t]{2}{*}{ FEV1 Change (litre) } & Median & 0.30 & 0.13 & $<0.01$ \\
\hline & Range & $0.19-0.46$ & $0.04-0.24$ & \\
\hline FEV1 change & Median & 15 & 8 & $<0.01$ \\
\hline (Reversibility \%) & Range & $12-19$ & $2-11$ & \\
\hline Need for oral steroids & Yes & 5 & 27 & $<0.01$ \\
\hline $\begin{array}{l}\text { during acute asthma } \\
\text { attack in the past } 12 \text { months }\end{array}$ & No & 100 & 48 & \\
\hline Need to increase rescue & Yes & 11 & 65 & $<0.01$ \\
\hline medications in the past 4 weeks & No & 94 & 10 & \\
\hline Need for maintenance & Yes & 11 & 63 & $<0.01$ \\
\hline medications in the past 4 weeks & No & 94 & 12 & \\
\hline
\end{tabular}

FEV1: Forced Expiratory Volume in one second. FVC: Forced Vital Capacity

Significant $\mathrm{P}$ values are written in bold lines 
Table 2: Demographic features, family history, history of allergy and prick test results of responders in comparison to nonresponders

\begin{tabular}{|c|c|c|c|c|}
\hline & & $\begin{array}{l}\text { Responders } \\
\mathrm{n}=105\end{array}$ & $\begin{array}{l}\text { Non responders } \\
n=75\end{array}$ & $P$ value \\
\hline \multirow[t]{2}{*}{ Age (year) n(\%) } & $<18$ & $23(21.9)$ & $13(17.3)$ & 0.20 \\
\hline & $\geq 18$ & $82(78.1)$ & $62(82.7)$ & \\
\hline \multirow[t]{2}{*}{ Duration of the disease (year) } & Mean & 15 & 15.8 & 0.30 \\
\hline & SD & 8.4 & 8.7 & \\
\hline \multirow[t]{2}{*}{ BMI $(\mathrm{Kg} / \mathrm{m} 2)$} & Mean & 27.5 & 27.4 & 0.50 \\
\hline & SD & 4.5 & 4.8 & \\
\hline \multirow[t]{2}{*}{ Gender $\mathrm{n}(\%)$} & Males & $56(53.3)$ & $41(54.6)$ & 0.80 \\
\hline & Females & $49(46.7)$ & $34(45.4)$ & \\
\hline \multirow[t]{2}{*}{ Smoking status $\mathrm{n}(\%)$} & Smokers & 25 & 23 & 0.30 \\
\hline & Non smokers & 80 & 52 & \\
\hline \multirow{2}{*}{ Family history of asthma $\mathrm{n}(\%)$} & Positive & $50(47.6)$ & $33(44.0)$ & 0.60 \\
\hline & Negative & $55(52.4)$ & $42(56.0)$ & \\
\hline \multirow[t]{2}{*}{ Associated allergic diseases $\mathrm{n}(\%)$} & Yes & $43(40.9)$ & $41(54.6)$ & 0.06 \\
\hline & No & $62(59.1)$ & $34(45.4)$ & \\
\hline \multirow[t]{2}{*}{ Skin test $\mathrm{n}(\%)$} & Positive & $48(45.7)$ & $41(54.6)$ & 0.20 \\
\hline & Negative & $57(54.3)$ & $34(45.4)$ & \\
\hline
\end{tabular}

BMI: Body Mass Index. SD: Standard Deviation

Table 3: Current treatment regimen of patients

\begin{tabular}{lllc}
\hline & Responders & Non responders & P value \\
\hline BD with low dose ICS & $\mathrm{n}=105$ & $\mathrm{n}=75$ & 0.40 \\
BD with medium dose ICS & 42 & 26 & 0.09 \\
BD with medium dose ICS and Oral corticosteroids & 23 & 25 & 0.40 \\
BD with medium dose ICS and Leukotriene antagonists & 3 & 1 & 0.10 \\
BD and Leukotriene antagonists & 11 & 13 & 0.06 \\
\hline
\end{tabular}

BD: Bronchodilators

ICS: Inhaled Corticosteroids

Table 4: The distribution of SLC22A4 (rs2073838 and rs3792876) SNPs among responders to bronchodilators and non-responders

\begin{tabular}{lcccc}
\hline & $\begin{array}{c}\text { Responders } \\
(105) \mathrm{n}(\%)\end{array}$ & $\begin{array}{l}\text { Non responders } \\
(75) \mathrm{n}(\%)\end{array}$ & P value & $\begin{array}{c}\text { Odds ratio } \\
(95 \% \text { CI })\end{array}$ \\
\hline rs2073838 & & & & \\
AA & $10(9.5)$ & $2(2.6)$ & 0.060 .2 & $(0.05-1.2)$ \\
AG and GG & $95(90.5)$ & $73(97.4)$ & 0.060 .0 & $3.8(0.8-18.1)$ \\
rs3792876 & & $13(17.3)$ & $\mathbf{0 . 0 1 3 . 4}$ & $(1.2-9.5)$ \\
TT & $6(5.7)$ & $62(82.7)$ & $\mathbf{0 . 0 1 0 . 0}$ & $0.2(0.1-0.8)$ \\
CT and CC & $99(94.3)$ & &
\end{tabular}

CI: Confidence Interval

Significant $\mathrm{P}$ values are written in bold lines

Table 5: SLC22A4 (rs2073838 and rs3792876) haplotypes distribution among responders to bronchodilators and non-responders

\begin{tabular}{|c|c|c|c|c|}
\hline Haplotype & $\begin{array}{l}\text { Responders } \\
(157) \mathrm{n}(\%)\end{array}$ & $\begin{array}{l}\text { Non responders } \\
(197) \mathrm{n}(\%)\end{array}$ & $\mathrm{P}$ value & $\begin{array}{l}\text { Odds ratio } \\
(95 \% \mathrm{CI})\end{array}$ \\
\hline $\mathrm{AC}$ & 54 & 25 & $<0.01$ & $0.5(0.29-0.8)$ \\
\hline AT & 17 & 23 & 0.07 & $1.8(0.9-3.5)$ \\
\hline GC & 90 & 60 & 0.10 & $0.7(0.4-1.1)$ \\
\hline GT & 36 & 49 & $<0.01$ & $2.0(1.2-3.3)$ \\
\hline
\end{tabular}

CI: Confidence Interval

Significant $\mathrm{P}$ values are written in bold lines 
Table 6: SLC22A4 (rs2073838 and rs3792876) genotypes distribution among subgroups of patients

\begin{tabular}{|c|c|c|c|c|c|c|c|}
\hline \multirow[b]{2}{*}{ Item } & \multirow[b]{2}{*}{ Groups } & \multicolumn{2}{|c|}{ rs2073838 } & \multirow[b]{2}{*}{$P$ value } & \multicolumn{2}{|c|}{ rs3792876 } & \multirow[b]{2}{*}{$\mathrm{P}$ value } \\
\hline & & AA & $\mathrm{AG}, \mathrm{GG}$ & & TT & $\mathrm{CT}, \mathrm{CC}$ & \\
\hline \multirow[t]{2}{*}{ Gender } & Male & 6 & 91 & 0.7 & 10 & 87 & 0.9 \\
\hline & Female & 6 & 77 & & 9 & 74 & \\
\hline \multirow[t]{2}{*}{ Age of onset } & $<18$ & 8 & 114 & 0.5 & 11 & 111 & 0.3 \\
\hline & $\geq 18$ & 3 & 55 & & 8 & 50 & \\
\hline \multirow[t]{2}{*}{ Associated allergic diseases } & Yes & 5 & 79 & 0.7 & 12 & 72 & 0.1 \\
\hline & No & 7 & 89 & & 7 & 89 & \\
\hline \multirow[t]{2}{*}{ Severity of asthma } & Mild & 4 & 96 & 0.1 & 11 & 89 & 0.8 \\
\hline & Moderate & 8 & 72 & & 8 & 72 & \\
\hline \multirow[t]{2}{*}{ Skin test } & Negative & 7 & 84 & 0.5 & 11 & 80 & 0.4 \\
\hline & Positive & 5 & 84 & & 8 & 81 & \\
\hline \multirow[t]{2}{*}{ Family history } & Negative & 6 & 90 & 0.8 & 9 & 87 & 0.5 \\
\hline & Positive & 6 & 78 & & 10 & 74 & \\
\hline
\end{tabular}

Supplementary Table 1: SLC22A4 (rs2073838 and rs3792876) genotypes and alleles distribution among responders and nonresponders

\begin{tabular}{llllll}
\hline rs2073838 & $\begin{array}{l}\text { Responders (105) } \\
\mathrm{n}(\%)\end{array}$ & $\begin{array}{l}\text { Non responders } \\
(75) \mathrm{n}(\%)\end{array}$ & rs3792876 & $\begin{array}{l}\text { Responders } \\
(105) \mathrm{n}(\%)\end{array}$ & $\begin{array}{l}\text { Non responders } \\
(75) \mathrm{n}(\%)\end{array}$ \\
\hline Genotype & & & Genotype & \\
AA & $10(9.6)$ & $2(2.7)$ & TT & $6(5.7)$ & $13(17.3)$ \\
AG & $47(44.7)$ & $29(38.6)$ & CT & $33(31.4)$ & $38(50.7)$ \\
GG & $48(45.7)$ & $44(58.7)$ & CC & $66(62.9)$ & $24(32.0)$ \\
Phenotype & & & Phenotype & & \\
A & $67(31.9)$ & $33(22.0)$ & T & $45(21.4)$ & $64(42.7)$ \\
G & $143(68.1)$ & $117(78.0)$ & C & $165(78.6)$ & $86(57.3)$ \\
\hline
\end{tabular}

The responding status to salbutamol was assessed in relation to the current therapeutic regimen of patients; results are illustrated in Table 3. There was no significant effect of the therapeutic regimen on the $\mathrm{BDR}$ results.

The genotype and allele frequencies of SLC22A4" rs3792876 and rs2073838" among cases are illustrated in the supplementary Table 1 . The distributions of the examined SNPs among cases are within HardyWeinberg Equilibrium. The frequency of rs2073838 genotypes showed no significant difference when compared among responders and non-responders. On the other hand, the recessive genotype of rs3792876 occurred more frequently among the non-responding patients $\mathrm{P}=0.01$. The differences in the frequencies of both SNPs among the two groups are illustrated in Table 4. Haplotype analysis of the two SNPs showed that the AC haplotype was more frequent in responders and the GT haplotype was more frequent in nonresponders $\mathrm{P}<0.01$, as shown in Table 5 .

Based on the gender, age of onset, family history, severity of asthma and the presence of atopy, patients were categorized into groups and the distribution of SLC22A4 genotypes within these groups were compared. No significant association of these factors with the distribution of genotypes was detected. Results are illustrated in Table 6.

\section{Discussion}

This study included 180 bronchial asthma patients admitted to the Chest clinic of Zagazig university hospital for follow up. Bronchodilator reversibility test was performed to categorize patients into responders and non-responders to salbutamol. $105(58.3 \%)$ patients were responders and $75(41.7 \%)$ were non-responders.

At first, comparison was made between the two groups regarding the baseline pulmonary function tests, severity of asthma, demographic criteria, family history and history allergy to exclude the presence of significant differences between responders and non-responders regarding these factors, as these factors may influence the responsiveness to bronchodilators rather than the examined SNPs. As indicated from previous studies such as; Heffler et al. (2016) how concluded that patients with lower baseline FEV1 had greater response to bronchodilator, Hegewald et al. (2012) who found that BDR had positive correlation with age and the absolute changes of FEV1 were significantly larger in men than women, while body mass index showed no effect on it, On the Controversy Dunn et al. (2015) concluded that increased risk of treatment failure is associated with older age, and sex has no association with it, and Ahmad and Singh (2010) concluded that there is a down-regulation of adrenergic receptors in smoker asthmatics.

To exclude the possible effect of the current treatment on the passage of Salbutamol through the 
organic cation transporters, we evaluated the responding status of patients in relation to the therapy and there were no significant effects. Chiappori et al. (2012) found out that corticosteroids increase Salbutamol transport through the OCT3 in human bronchial smooth muscle cell lines, although this increase was not significant but this point requires further in vivo investigations.

The difference of frequencies of both SNPs was examined among responders and non-responders, a significant association between (rs3792876) and bronchodilators resistance was detected, as the recessive phenotype (TT) was more frequent in non-responders group rather than the responders. While for (rs2073838) a significant association was not detected. In addition, the GT haplotype was more frequent in non-responders and $\mathrm{AC}$ was more frequent in responders. The genotype distribution of rs2073838 in both groups did not differ significantly from the distribution in normal populations studied in previous literatures such as Plenge et al., (2005) study on north American and Sweden populations (Plenge et al., 2005). For rs3792876, the distribution in responders goes with that in previous studies while in non-responders the distribution differs significantly from normal populations (Hou et al., 201; Jaruskova et al., 2017; Angelini et al., 2013; De Ridder et al., 2007; Barton et al., 2005; Shahidi and Fitzgerald, 2010; Koskela et al., 2006; Poon et la., 2012; Larocca et al., 2013; Newman et al., 2005; Charan and Biswas, 2013; Heffler et al., 2016; Hegewald et al., 2012; Dunn et al., 2015; Ahmad and Singh, 2010; Chiappori et al., 2012; Plenge et al., 2005; Santiago et al., 2006). Finally, none of the studied genotypes was associated with gender, age of onset, positive family history, history of atopy or asthma severity.

Up to our knowledge, no previous literature studied the association between SLC22A4 gene polymorphisms and response to bronchodilators in asthmatic patients.

Horvath et al found that mRNA of OCTN1, as well as OCTN2, were highly expressed in airway epithelia of the lung tissue and the OCTN1 activity was largely associated with the apical border of the epithelial cell in the trachea, also, they found that Albuterol and formoterol inhibited the in vitro uptake of a cationic fluorophore, suggesting the involvement of OCTN1/2 of the airway epithelial cells in the delivery of inhaled cationic bronchodilators to the underlying tissues (Horvath et al., 2006).

Although previous studies confirmed the expression of these transporters in lung tissues and its role in transporting cationic drugs through the epithelial layer of trachea and bronchioles via cell line based transporting methods, clinical evidence on these data are still inadequate (Ehrhardt et al., 2017). Drake et al. (2014) found a significant increase in bronchodilator response in association with two rare SNPs in the SLC22A15 gene rs1281748 and rs1281743 Drake et al. (2014), this finding indicates the possible influence of Organic Cation Transporter polymorphisms on the response to inhaled bronchodilator.

\section{Limitations and Replication Studies}

The calculated sample size was the minimum required to achieve an $80 \%$ statistical power of the study. Because of the deficiency of previous results concerning the association of SLC22A4 gene polymorphism "particularly the studied SNPs" and the bronchodilator responses, as well as the relatively small sample size and the lack of funding sources, replication studies with larger sample size and more statistical power including both asthmatic and non-asthmatic normal populations are recommended to confirm or deny these results.

\section{Conclusion}

The homozygous form of (rs3792876) in the RUNX1 binding site in SLC22A4 gene can interfere with the absorption of inhaled bronchodilator (Salbutamol), although, further investigations on this point are required.

\section{Recommendations}

We recommend expanding this study on other Organic Cation Transporters polymorphisms, in relation to other drugs in the Bronchial Asthma therapy.

\section{Conflict of Interest}

Authors have no conflict of interest to declare.

\section{Funding Sources}

This research did not receive any specific grant from funding agencies in the public, commercial, or not-forprofit sectors.

\section{Author Contributions}

The requirements for authorship have been met. The original idea was the first authors, who also performed the data analysis, manuscript writing and submission for publication. The second author contributed to sample processing, results collection and participated in manuscript writing. The third author contributed to allergy skin prick test performance, clinical diagnosis of patients, history taking and manuscript revision. The fourth author contributed to the clinical diagnosis of patients, history taking, spirometry, blood samples withdrawal and manuscript revision. Authors certify 
that we have personally written at least 90 percent of the manuscript. Finally, the manuscript has been read and approved by all the authors.

\section{References}

Ahmad, Z. and S.K. Singh, 2010. Relative and additional bronchodilator response of salbutamol and ipratropium in smoker and nonsmoker asthmatics. J. Asthma: Official J. Association Care Asthma., 47: 340-343. DOI: 10.3109/02770900903584456

Angelini, S., S. Soverini, G. Ravegnini, M. Barnett and E. Turrini et al., 2013. Association between imatinib transporters and metabolizing enzymes genotype and response in newly diagnosed chronic myeloid leukemia patients receiving imatinib therapy. Haematologica, 98: 193-200. DOI: $10.3324 /$ haematol.2012.066480

Ayrton, A. and P. Morgan, 2008. Role of transport proteins in drug discovery and development. A pharmaceutical perspective. Xenobiotica Fate Foreign Comp. Biol. Syst., 38: 676-708.

DOI: 10.1080/00498250801923855

Barton, A., S. Eyre, J. Bowes, P. Ho and S. John et al., 2005. Investigation of the SLC22A4 gene (associated with rheumatoid arthritis in a Japanese population) in a United Kingdom population of rheumatoid arthritis patients. Arthritis Rheumatism, 52: 752-758. DOI: 10.1002/art.20877

Charan, J. and T. Biswas, 2013. How to calculate sample size for different study designs in medical research? Indian J. Psychol. Med., 35: 121-126.

DOI: 10.1002/art.20854

Chiappori, A., C. Folli, A.M. Riccio E. Caci and D. Descalzi et al., 2012. Salbutamol: how does it enter smooth muscle cells? Int. J. Immunopathol. Pharmacol., 25: 541-546.

DOI: $10.1177 / 039463201202500227$

Chung, K., P. Godard, E. Adelroth, J. Ayres and N. Barnes et al., 1999. Difficult/therapy-resistant asthma: the need for an integrated approach to define clinical phenotypes, evaluate risk factors, understand pathophysiology and find novel therapies. ERS Task Force on Difficult/TherapyResistant Asthma. Eur. Respir. Soc. Eur. Respiratory J., 13: 1198-1208.

De Ridder, L., R.K. Weersma, G. Dijkstra, G.V.D. Steege and M.A. Benninga et al., 2007. Genetic susceptibility has a more important role in pediatriconset Crohn's disease than in adult-onset Crohn's disease. Inflammatory Bowel Dis., 13: 1083-1092. DOI: 10.1002/ibd.20171

Drake, K.A., D.G. Torgerson C.R. Gignoux, J.M. Galanter and L.A. Roth et al., 2014. A genome-wide association study of bronchodilator response in Latinos implicates rare variants. J. Allergy Clin. Immunol., 133: 370-378. DOI: 10.1016/j.jaci.2013.06.043
Dunn, R.M. E. Lehman., V.M. Chinchilli, R.J. Martin, H.A. Boushey et al., 2015. Network NACR Impact of age and sex on response to asthma therapy. Am. J. Respire. Critical Care Med., 192: 551-558. DOI: $10.1164 / \mathrm{rccm} .201503-04260 \mathrm{C}$

Ehrhardt, C., P. Backman, W. Couet, C. Edwards and B. Forbes et al., 2017. Current progress toward a better understanding of drug disposition within the lungs. J. Pharm. Sci., 106: 2234-2244. DOI: $10.1016 /$ j.xphs.2017.04.011

Gründemann, D., J. Babin-Ebell, F. Martel, N. Örding and A. Schmidt et al., 1997. Primary structure and functional expression of the apical organic cation transporter from kidney epithelial LLC-Pk1cells. J. Biol. Chem., 272: 10408-10413

Grundemann, D., S. Harlfinger, S. Golz, A. Geerts and A. Lazar, 2005. Discovery of the ergothioneine transporter. Proceedings of the national academy of sciences of the United States of America, (USA' 2005).

Heffler, E., C. Crimi, R. Campisi, S. Sichili and G. Nicolosi, 2016. Bronchodilator response as a marker of poor asthma control. Respir. Med., 112: 45-50. DOI: $10.1002 /$ art.20854

Hegewald, M.J., R.G. Townsend, J.T. Abbott and R.O. Crapo, 2012. Bronchodilator response in patients with normal baseline spirometry Respiratory Care, 57: 1564-1570. DOI: 10.4187/respcare.01537

Horvath, G., N. Schmid, M.A. Fragoso, A. Schmid and G.E. Conner et al., 2007. Epithelial organic cation transporters ensure $\mathrm{pH}$-dependent drug absorption in the airway. Am. J. Respir. Cell Molecular Biol., 36: 53-60. DOI: 10.1165/rcmb.2006-0230OC

Hou, X., J. Mao, Y. Li, J. Li and W. Wang et al., 2015. Association of single nucleotide polymorphism rs3792876 in SLC22A4 gene with autoimmune thyroid disease in a Chinese Han population. BMC Med. Genet.

Jaruskova, M., N. Curik, R. Hercog, V. Polivkova and E. Motlova, et al., 2017. Genotypes of SLC22A4 and SLC22A5 regulatory loci are predictive of the response of chronic myeloid leukemia patients to imatinib treatment. J. Exp Clin. Cancer Res.

Kekuda, R., P.D. Prasad, X. Wu, H. Wang and Y.J.F. Leibach 1998. Cloning and functional characterization of a potential-sensitive, polyspecific organic cation transporter (OCT3) most abundantly expressed in placenta. J. Biol. Chem., 273: 15971-9. DOI: $10.1074 /$ jbc.273.26.15971

Koepsell, H. and H. Endou, 2004. The SLC22 drug transporter family. Pflugers Archiv. Eur. J. Phys., 447: 666-676. DOI: 10.1007/s00424-003-1089-9

Koepsell, H. and H. Endou, 2004. The SLC22 drug transporter family. Pflügers Archiv. 447: 666-76. DOI: $10.1007 / \mathrm{s} 00424-003-1089-9$ 
Koskela, H.O., V. Kiviniemi, M.K. Purokivi, A.H. Taivainen and H.O. Tukiainen, 2006. Determinants of the bronchodilation response to salbutamol on histamine-induced bronchoconstriction. Respir. Med., 100: 1760-1766.

Larocca, N., D. Moreno, J.V. Garmendia, O. Velasquez and J. Martin-Rojo et al., 2013. Beta 2 adrenergic receptor polymorphisms, at codons 16 and 27 and bronchodilator responses in adult Venezuelan asthmatic patients. Biomed Pap Med Fac Univ Palacky Olomouc Czech Repub., 157: 374-378. DOI: $10.5507 / \mathrm{bp} .2012 .084$

Li, X., E.J. Ampleford, T.D. Howard, W.C. Moore and D.G. Torgerson et al., 2012. Genome-wide association studies of asthma indicate opposite immunopathogenesis direction from autoimmune diseases. J. Allergy Clin. Immunol., 130: 861-8. DOI: 10.1016/j.jaci.2012.04.041

Lima, J.J., K.V. Blake, K.G. Tantisira and S.T. Weiss, 2009. Pharmacogenetics of asthma. Current Opinion Pulmonary Med., 15: 57-62.

DOI: 10.1097/MCP.0b013e32831da8be

Nakahara, S., Y. Arimura, K. Saito, A. Goto and S. Motoya et al., 2008. Association of SLC22A4/5 polymorphisms with steroid responsiveness of inflammatory bowel disease in Japan. Diseases Colon Rectum, 51: 598-603.

DOI: $10.1007 / \mathrm{s} 10350-008-9208-5$

Newman, B., R.F. Wintle, M. van Oene, M. Yazdanpanah and J. Owen et al., 2005. SLC22A4 polymorphisms implicated in rheumatoid arthritis and Crohn's disease are not associated with rheumatoid arthritis in a Canadian Caucasian population. Arthritis Rheumatism, 52: 425-429. DOI: 10.1002/art.20854

Okuda, M., H. Saito, Y. Urakami, M. Takano and K. Inui et al. 1996. CDNA cloning and functional expression of a novel rat kidney organic cation transporter, OCT2. Biochemical Biophysical Res. Communications, 224: 500-7.

DOI: $10.1006 /$ bbrc. 1996.1056

Pauwels, R.A., 1996. Global strategy for asthma management and prevention. Nat. Heart, Lung Blood Ins., 45: 8-9. DOI: 10.15036/arerugi.45.792

Peltekova, V.D., R.F. Wintle, L.A. Rubin, C.I. Amos and Q. Huang et al., 2004. Functional variants of OCTN cation transporter genes are associated with Crohn disease. Nat. Genet., 36: 471-5. DOI: $10.1038 / n g 1339$

Plenge, R.M., L. Padyukov, E.F. Remmers, S.Purcell and A.T. Lee et al., 2005. Replication of putative candidate-gene associations with rheumatoid arthritis in> 4,000 samples from North America and Sweden: association of susceptibility with PTPN22, CTLA4 and PADI4. Am. J. Human Genet., 77: 1044-1060. DOI: $10.1086 / 498651$
Poon, A.H., D.H. Eidelman, J.G. Martin, C. Laprise and Q. Hamid, 2012. Pathogenesis of severe asthma. Clinical and experimental allergy. J. British Soc. Allergy Clin. Immunol., 42: 625-637. DOI: 10.1111/j.1365-2222.2012.03983.X

Sakamoto, A., T. Matsumaru, N. Yamamura, Y. Uchida and M. Tachikawa et al., 2013. Quantitative expression of human drug transporter proteins in lung tissues: analysis of regional, gender and interindividual differences by liquid chromatography-tandem mass spectrometry. J. Pharm. Sci., 102: 3395-406.

DOI: 10.1002/jps.23606

Santiago, J.L., A. Martínez, H. de la Calle, M. Fernández-Arquero and M.Á. Figueredo et al., 2006. Evidence for the association of the SLC22A4 and SLC22A5 genes with type 1 diabetes. A case control study. BMC Med. Genet.

DOI: $10.1186 / 1471-2350-7-54$

Santiago, J.L., A. Martinez, H.D.L. Calle, M. FernandezArquero and M.A. Figueredo, et al., 2006. Evidence for the association of the SLC22A4 and SLC22A5 genes with type 1 diabetes: A case control study. BMC Med. Genetic.

Shahidi, N. and J.M. Fitzgerald, 2010. Current recommendations for the treatment of mild asthma. J. Asthma Allergy, 3: 169-176.

DOI: $10.2147 /$ JAA.S14420

Soriano, J.B., A.A. Abajobir, K.H. Abate, S.F. Abera and A. Agrawal et al., 2017. Global, regional and national deaths, prevalence, disability-adjusted life years and years lived with disability for chronic obstructive pulmonary disease and asthma, 1990-2015: a systematic analysis for the Global Burden of Disease Study 2015. Lancet Respir. Med., 5: 691-706. DOI: 10.1016/S2213-2600(17)30293-X

Tamai, I., H. Yabuuchi, Y. Nezu, A. Sai Oku and M. Shimane et al., 1997. Cloning and characterization of a novel human pH-dependent organic cation transporter, OCTN1. FEBS Lett., 419: 107-11. DOI: $10.1016 / \mathrm{S} 0014-5793(97) 01441-5$

Tarnoki, D.L., E. Medda, A.D Tarnoki, A. Bikov and Z. Lazar et al., 2015. Modest genetic influence on bronchodilator response: A study in healthy twins. Croat. Med. J., 56: 152-8 DOI: $10.3325 / \mathrm{cmj} .2015 .56 .152$

Tokuhiro, S., R. Yamada, X. Chang, A. Suzuki and Y. Kochi et al., 2003. An intronic SNP in a RUNX1 binding site of SLC22A4, encoding an organic cation transporter, is associated with rheumatoid arthritis. Nat. Genet., 35: 341-8. DOI: 10.1038/ng1267

Zhou, F. and G. You, 2007. Molecular insights into the structure-function relationship of organic anion transporters OATs. Pharm. Res., 24: 28-36. DOI: $10.1007 / \mathrm{s} 11095-006-9144-9$ 